\title{
FORMAÇÃO PÓS-GRADUADA: (RE)INVENTANDO IDENTIDADES
}

\author{
Posgraduate education: inventing identities
}

\author{
France Fraiha Martins \\ Inês Trevisan \\ Mônica Gonçalves de Matos ${ }^{3}$ \\ Terezinha Valim Oliver Gonçalves ${ }^{4}$
}

\section{RESUMO}

Discutimos, neste artigo, experiências de formação docente e de pesquisa vividas em nível de mestrado, a partir de manifestações escritas dos sujeitos investigados. Objetivamos investigar questões vinculadas ao processo de formação pós-graduada que emergem durante o percurso de convivência na academia, em que os sujeitos - mestrandos em Educação em Ciências e Matemática - e os demais personagens do contexto investigativo, imbuídos de suas crenças, valores, incertezas e identidades, passam a interagir uns com os outros, transformando-se a partir das interações, produzindo trocas múltiplas e revivendo a cada 'troca', a cada texto e a cada 'crise' sua própria história e percurso de formação. Este é um recorte de uma pesquisa mais ampla sobre formação pós-graduada desenvolvida com dezessete mestrandos. Na perspectiva da análise textual discursiva, no contexto de uma pesquisa narrativa, os depoimentos individuais dos sujeitos foram organizados em duas categorias: i) Experiências formativas (re)significando as ações docentes; ii) Identidades culturais e a formação pós-graduada. A análise dos resultados revela os sentidos e significados que os mestrandos atribuem ao seu processo de formação pós-graduada, assumindo serem (co)responsáveis pelo próprio processo de formação, na medida em que se tornam sujeitos com intencionalidades explícitas no ato de aprender. O processo de formação reflexiva pelo qual passam promove (re)construção de sua identidade profissional, tendo em vista o intercâmbio que se estabelece na academia, formando uma rede de significados compartilhados que possui sentido individual e coletivo. Ao refletirmos sobre as narrativas dos sujeitos envolvidos, pudemos também refletir sobre as nossas próprias trajetórias de vida e formação, buscando cada vez mais a compreensão e a importância da contínua formação, da clareza do ser inacabado, do aprender a aprender.

Palavras-chave: Formação docente. Formação do pesquisador. Processo identitário.

\begin{abstract}
This article discuss the experiences of teacher education and research experienced in master'slevel, based on written statements of the subjects investigated. We aimed to investigate issues relating to the process of postgraduate education that emerge during the course of living in the gym, where the subjects - Masters in Education in Mathematics and Science - and the other characters in the research context, imbued with their beliefs, values, uncertainties and identities, they began by interacting with each other, transforming themselves from interactions, producing multiple exchanges and reliving every 'change', every text and every 'crisis' history and their own educational path. This is an excerpt from a larger study on postgraduate education developed with seventeen masters. From the perspective of discursive textual analysis in the context of a narrative research, the individual statements of the subjects were classified into two categories: i) formative experiences reconstructing meanings of the teachers' actions, ii) Cultural identity and the postgraduate education. The results reveal the meanings they attach to their masters the process of postgraduate education, assuming they are responsible for their formation process, as they become subject to explicit intentions in learning. The education process by which are reflective
\end{abstract}

\footnotetext{
${ }^{1}$ Mestranda do Programa de Pós-graduação em Educação em Ciências e Matemáticas (PPGECM/NPADC/UFPA.

${ }^{2}$ Mestranda do Programa de Pós-graduação em Educação em Ciências e Matemáticas (PPGECM/NPADC/UFPA)

${ }^{3}$ Mestranda do Programa de Pós-graduação em Educação em Ciências e Matemáticas (PPGECM/NPADC/UFPA)

${ }^{4}$ Docente do Programa de Pós-graduação em Educação em Ciências e Matemáticas (PPGECM/NPADC/UFPA)
} 
promotes reconstruct their professional identity in order, the exchange that takes place in the academy, forming a network of shared meanings that are individual and have collective sense. Reflecting the narratives of those involved, we also reflect on our own paths of life and training, looking for more understanding and also the importance of continuous education, the clarity of being unfinished, of learning to learn.

Keywords: Teacher education. Education of the investigator. Identity process.

\section{COMPARTILHANDO UM DISCURSO...}

Vivenciamos um momento histórico de profundas transformações na estrutura científica e social. Ter conhecimento específico em uma determinada área do conhecimento não basta para desenvolvermos nossas atividades docentes. Estas não mais se reduzem a uma questão técnica de transmissão de conhecimentos estabelecidos a priori e planejados por outros, mas estão imersas em um contexto onde ser professor implica em ter a capacidade de " $[\ldots]$ tomar decisões educativas, éticas e morais, de desenvolver o currículo em um determinado contexto e de elaborar projetos e materiais curriculares com a colaboração dos colegas[...] (IMBERNÓN, 2005. p. 21).

Nesse contexto de mudanças dos papéis educativos - escola, professores e alunos -, na era da informação, nós, professores, somos convidados a repensar nossas práticas, revisar as teorias que, assumidas ou não, norteiam nosso fazer pedagógico. Estamos em um momento em que a questão da competência do professor é abordada como fator imprescindível para a superação do paradigma tradicional de ensino, já que as ambições dos sistemas educacionais exigem novos conhecimentos e formas de agir em sala de aula.

Dessa maneira, a necessidade de termos cursos de formação continuada que deem ênfase às práticas colaborativas de desenvolvimento do conhecimento profissional é condição imperativa para uma nova postura educativa. $\mathrm{O}$ trabalho colaborativo é considerado um modo eficaz de os profissionais enfrentarem os problemas e desafios da sua prática, mediante um mundo de incertezas e constantes mudanças (FIORENTINI; NACARATO, 2005).

Temos consciência de que os conteúdos conceituais, factuais, procedimentais e atitudinais - que conseguimos compreender na formação inicial não são suficientes nem tão duradouros num tempo de grandes mídias interativas que propiciam o acesso acelerado às informações, num processo multidirecional, a uma parcela considerável da população. Tempo em que o presente já é passado e o futuro torna-se rapidamente o agora.

Nesses termos, não podemos mais acreditar - seria no mínimo ingênuo - que o conhecimento adquirido no início de carreira seja suficiente e nos sirva durante toda a nossa vida.

Nosso desenvolvimento profissional dependerá das escolhas que fizermos. Podemos permanecer inertes ou discursar alicerçados por diversas justificativas, como, por exemplo, aguardar que os políticos de boa vontade façam acontecer o progresso educacional tão sonhado por muitos professores. Podemos, de outro modo, ir em busca de subsídios teóricos e metodológicos que ancorem a construção de outras/novas ações docentes e utilizá-las de forma consistente e consciente.

Compartilhamos com Nóvoa (1988. p. 129) a compreensão de que " formar não é ensinar às pessoas determinados conteúdos, mais sim trabalhar coletivamente em torno da resolução de problemas. A formação faz-se na 'produção', e não no 'consumo'. Essa ideia de consumidores de conhecimento que, por muitos anos, estruturou os cursos de formação de professores dá lugar a novas concepções e formatos de cursos de formação inicial e continuada.

É com esse entendimento de sujeitos construtores do seu próprio saber e como um ser em mudança que pensamos na importância dos cursos de formação continuada, sobretudo, cursos de pós-graduação em nível de mestrado. Entendemo-los como oportunidades de formação que podem propiciar aos seus participantes não apenas "atualização científica, pedagógica e cultural [...]", [mas também] a "descoberta da teoria para organizá-la, fundamentá-la, revisá-la e combatê-la, se 
preciso", ou seja, pensamos os momentos de formação como oportunidades de reflexão sobre si(IMBERNÓN, p. 69).

Nessa perspectiva, o processo reflexivo propiciado pela formação continuada é uma oportunidade de redescoberta de si como profissional, que pode "tomar consciência de que este reconhecimento de si mesmo como sujeito, mais ou menos ativo ou passivo segundo circunstâncias, permite à pessoa [...] encarar 0 seu itinerário de vida [...]" em constante transformação(JOSSO 2004. p. 58).

\section{CON T EX T UA L I Z A N O NOSSA INVESTIGAÇÃO}

Direcionamos nosso estudo para a compreensão dos sentidos e significados que os sujeitos atribuem ao seu processo de formação num contexto de pós-graduação em nível de mestrado em Educação em Ciências e Matemáticas numa universidade pública federal da região norte do Brasil.

Este estudo é parte de uma pesquisa mais ampla sobre formação pós-graduada, desenvolvida com dezessete mestrandos, ingressos em 2007, no Programa em foco. Para este artigo, foram tomados os textos narrativos de dois desses sujeitos, aqui denominados, ficticiamente, de Fernando e Letícia.

Esse grupo é formado por quatro pedagogos, seis biólogos, quatro matemáticos, dois educadores físicos, um tecnólogo em processamento de dados e uma professoraformadora. Nós, autoras deste artigo, também faziamos parte desse grupo. Todos atuam profissionalmente como professores.

Buscamos compreender num movimento individual e coletivo o processo de formação pelo qual nossos colegas estão passando e assim compreender a nós mesmas e as experiências vivenciadas por alunos pós-graduandos em formação, pois, entendemos, com Josso (2004, p.42), que "o processo de formação dá-se a conhecer por meio dos desafios e apostas nascidas da dialética entre a condição individual e a condição coletiva".

Interessa-nos saber, então, como, nos seus percursos de vida e, sobretudo, no momento de formação em que se encontram, os mestrandos construíram e reconstruíram concepções acerca do seu desenvolvimento profissional. Como essas concepções foram sofrendo mudanças ao longo de seu percurso de formação pósgraduada? Se ocorreram mudanças interiores, mudaram suas percepções sobre a prática docente? Em síntese: O que revelam os mestrandos em Educação em Ciência e Matemática, a respeito de sua formação pósgraduada?

Investigar possíveis respostas às indagações que nos fizemos e apontar caminhos para a compreensão do processo de formação ao longo da vida é o que buscamos com esta pesquisa. Temos clara intenção de expressar que as ideias aqui expostas são apenas algumas das opções possíveis de interpretação desse processo de formação pós-graduada do qual fazemos parte.

\section{ANUNCIANDO NOSSAS OPÇÕES METODOLÓGICAS}

Neste estudo, de natureza qualitativa, optamos por relatar experiências de formação vividas por mestrandos e narradas por meio de um processo de auto-reflexão textual, intitulada Reflexões sobre minha formação pós-graduada: um processo em construção, realizada por solicitação da coordenadora da pesquisa..

Optamos pelo emprego dessa estratégia de busca de informações, por entendermos que o texto individual possibilitaria ao mestrando rever sua trajetória profissional e o processo de formação pelo qual está passando, numa perspectiva auto-avaliativa, em um processo reflexivo.

Trabalhar com histórias de vida e formação representa rememorar, possibilitando realizar uma volta ao passado e perceber seus reflexos no presente, fazendo projeções para o futuro. Assim como propõe Josso ( 2004. p. 60), entendemos que é no decurso desta situação, em que o presente é articulado com o passado e com o futuro, que começa, de fato, a elaborar-se um projeto para si por um sujeito que orienta a continuação da sua história.

Nessa perspectiva, trazemos à tona as impressões, dúvidas, angústias e aspirações dos 
sujeitos investigados, por meio da pesquisa narrativa (CONELLY; CLANDININ, 1995), como opção metodológica. Para tanto, utilizamos os depoimentos dos sujeitos para a construção de dados, que são analisados por meio da análise textual discursiva (MORAES; GALIAZZI, 2007).

Ao examinarmos o "corpus", através da desconstrução, unitarização e categorização dos textos, buscamos núcleos de sentido, que possibilitaram uma compreensão mais profunda acerca de pensamentos, concepções e sentimentos dos mestrandos que manifestam perceber estar num processo de construção formativa.

De cada manifestação, selecionamos excertos com ideias recorrentes entre os investigados e procuramos destacar palavraschave, que representassem o núcleo das ideias expostas pelos depoimentos destacados, emergindo assim duas categorias de análise: i) Experiências formativas resignificando as ações docentes e, ii) Identidades culturais e a formação pós-graduada.

Desta maneira, optamos por explicitar nas análises o que é recorrente entre as ideias dos sujeitos, objetivando trazer reflexões sobre a importância da formação contínua e dos possíveis desdobramentos que poderão ocorrer no âmbito do desenvolvimento profissional.

Portanto, a partir das ideias expressas pelos mestrandos investigados, pretendemos inferir sentidos e significados a questões voltadas para as experiências formativas, compreendendo, com JOSSO (2004, p.38), que "as narrativas de formação nos servem de material para compreender os processos de formação, de conhecimento e de aprendizagem".

Passamos, a seguir, a discutir/apresentar as duas categorias de análises que emergiram dos textos narrativos, anteriormente referidas.

\section{Experiên cias formativas resignificando as ações docentes}

Buscando a compreensão das ideias dos sujeitos selecionados, ficou claro, para nós, como mensagem central,que os sujeitos manifestam uma grande satisfação em estar vivendo um pocesso de formação pós-graduada.

Ao narrarem suas experiências formativas vivenciadas no âmbito do mestrado, evidenciaram de modo marcante situações de interatividade e leituras acadêmicas que foram fundamentais para auto-reflexões sobre suas ações na busca de resiginificar suas práticas. Portanto, situações de interatividade e leituras acadêmicas, por terem emergido de forma expressiva nas análises, foram tomadas como subcategorias que ora daremos a conhecer.

\section{Situações de interatividade}

As interações formativas que vivenciamos no contexto do curso de mestrado, no qual convivemos com colegas profissionais - como Fernando e Letícia - interessados em refletir e construir conhecimentos voltados para a educação em ciências e matemática, possibilitaram aprendizagens que nos levam a um auto-conhecimento (SANTOS, 2005) e nos proporcionam mundanças interiores no que se refere ao nosso ser e fazer pedagógico.

Relatar uma prática vivida, desabafar uma frustração didática, contar angústias existentes, discordar de determinados autores, narrar atuações de êxito, defender suas concepções, ou, ainda dito de outro modo, interagir com profissionais - alunos/colegas e professores - num contexto de diversidade social e cultural, trazendo discussões teóricas e práticas, epistemológicas e metodológicas, contribuiram significativamente em nossa formação pós-graduada. Da mesma forma, Letícia em suas reflexões também deixa evidente que as interações mantidas com outros mestrandos e seus professores-formadores lhes possibilitaram aprendizagens que a remeteram a um auto-conhecimento por vezes surpreendente, mundando atitudes e pensamentos. 
[...] a forma como o professor conduziu as aulas ampliou os olhares. As discussões a cada dia nos surpreendiam. Entendo que um educador tem que ter ouvidos sensíveis e olhares atentos e é justamente isso que a Semiótica proporciona: amplitude no olhar e sensibilidade no ouvir (Letícia).

Letícia explicita a importância do papel do professor como mediador na construção do conhecimento do grupo em que estava inserida. A dinâminca da interatividade experienciada atribuída à forma como o professor conduziu as aulas e as discussões realizadas na sala de aula entre professor e mestrandos resultou em situações concretas de ensino e de aprendizagem que remeteram a uma resignificação do que é ser um educador.

Colomina, Onrubia e Rocheda (2004, p.298) afirmam que a interatividade ocorre tanto pelas trocas comunicativas face a face entre professor e alunos como também por meio de situações mais amplas individualizadas e que juntos assumem seu significado educacional, ou seja, a interatividade possibilita dar significados e sentidos ao que se busca aprender remetendo a um duplo processo de construção: "das aprendizagens que os alunos realizam e da própria atividade conjunta que professor e alunos realizam" (2004, p.300). Neste sentido, diz Letícia:

Um elo. Foi a conclusão que cheguei ao refletir sobre minha formação pósgraduada ainda em construção. Todas as disciplinas que fui fazendo foram automaticamente se articulando entre si e com as discussões realizadas nos grupos de estudo dos quais participei [...]. Nesses grupos, pude ter acesso a histórias vividas, relatos de experiências, apresentação de projetos e discussões de artigos imbuídos de vários assuntos relacionados à educação em ciëncias e matemática (Letícia).

Do mesmo modo, valoriza a interatividade vivida entre os mestrandos durante as discussões realizadas nos grupos de estudos como oportunidade de (auto)formação que considera importante para sua prática docente, pois destaca que cada integrante ao narrar suas histórias de vida, relatar experiências, apresentar projetos e discutir artigos forma interconexões com os colegas, os professores e os autores, gerando uma grande teia de aprendizagem.

Compreendemos com Nóvoa (1992, p.26)

que é importante a criação de redes de (auto)formação participada, que permitam compreender a globalidade do sujeito, assumindo a formação como processo interativo e dinâmico. A troca de experiência consolida espaços de formação mútua, nos quais cada professor é chamado a desempenhar, simultâneamente, o papel de formador e de formando.

Se refe renciarmos ainda a aprendizagem do indivíduo abordada por Vigotsky, podemos reiterar o papel ativo de cada integrante do grupo de estudo, como sujeito interativo, que se relaciona com o mundo, com os outros indivíduos, com o contexto social em que está inserido, ou seja, é a partir da interatividade com o meio externo - grupo de estudo - capaz de produzir reflexões pessoais, que o indivíduo apreende e internaliza algo, dando-lhe um significado pessoal e próprio.

Nesses termos, compreendemos as situações de interatividade proporcionadas no âmbito do programa de pós-graduação em questão como fator fundamental para a construção do processo de ensinar e aprender, podendo favorecer a reflexão e a reestruturação dos pontos de vista pessoais e, como consequência, a aprendizagem e o avanço intelectual.

\section{Leituras Acadêmicas}

As oportunidades de leituras acadêmicas, que vão além das simples leituras decifrativas como parte integrante das dinâmicas formativas em nosso contexto investigativo, tem nos proporcionado uma aproximação com referenciais teóricos que nos remetem a outras/novas reflexões acerca da docência. Fernando e Letícia expressam claramente as contribuições dos autores estudados no campo pessoal e profissional.

À medida que avanço nas leituras amadureço meu senso crítico, o que me leva a ser mais reflexivo e cético diante da realidade teórica pela qual estou passando (Fernando). 
Fernando explicita a reestruturação do pensamento no momento em que se acerca dos novos conhecimentos - por meio das leituras - e como ele está agindo/reagindo a partir da apropriação desses conhecimentos. Da mesma forma, Letícia afirma que:

[...] a partir dessas releituras reflexivas pude ter certeza que já não tenho o mesmo olhar, existe um novo olhar, despertou uma nova professora, um novo ser humano (Letícia).

Ambos destacam de modo enfático as contribuições dos autores-pesquisadores no que se refere a mudanças atitudinais e conceituais frente à literatura da área que estão tendo oportunidade de conhecer. Neste sentido, entendemos que a leitura reflexiva e crítica pode promover uma mudança democrática e emancipatória no sujeito com ela envolvido (FREIRE, 2006). Segundo Fernando e Letícia, eles experimentaram, a partir das leituras acadêmicas, o desenvolvimento da consciência crítica, pois foram encorajados a a lerem reflexivamente, posicionando-se sempre que necessário, concordando, resistindo e até mesmo negando as possíveis maneiras de ler o mundo. Essa prática lhes possibilitou construir amadurecimento do senso crítico, um novo olhar, um novo ser humano.

Nessa perspectiva, Baynham (1995), citado por Benevides (2002), diz que entender a leitura como processo, observando os lugares e os contextos em que ela ocorre, leva-nos a compreender que os leitores agem a partir de diversos lugares de interpretação, produzindo diversas leituras, o que o autor denomina de os efeitos da leitura. Tais efeitos estão associados a possíveis leituras que evidenciam posições de "resistência", ou seja, leituras que não aceitam as ideias como dadas, mas que questionam de onde elas procedem, como disse Fernando: - o que me leva a ser mais reflexivo e cético diante da realidade teórica pela qual estou passando. Fernando torna-se questionador frente às novas ideias, busca relacioná-las com conhecimentos e experiências anteriores, reconhecendo-se mais crítico e reflexivo.

Identificamos também nas manifestações de Fernando a internalização das teorias estudas por meio das leituras acadêmicas de tal forma que assumiu para si as concepções defendidas pelos autores estudados.

Foram muitas as contribuições de Boaventura Santos em relação a minha fundamentação teórica sobre os povos indígenas $[. .$.$] todo conhecimento é uma$ prática social de conhecimentos, ou seja, só existe na medida em que é protagonizado e mobilizado por um grupo social (Fernando).

Como participantes desse espaço de investigação, podemos inferir que as leituras no âmbito do mestrado efetivamente (re)constroem, (trans)formam e nos (re) formam, como diz Freire (1998), revelando-nos diferentes identidades a cada tempo e espaço pelos quais passamos em nosso cotidiano do processo de formação pós-graduada.

As experiências formativas acima analisadas - situações de interatividade e leituras acadêmicas - são valorizadas pelos sujeitos investigados como processos importantes para a formação do profissional crítico e reflexivo (Alarcão, 2007), para a formação de novos olhares sobre a formação e a profissão, o que, certamente, lhes possibilitará a formação pós-graduada desejada, visando ao desenvolvimento profissional diferenciado de professor e pesquisador na área de Ensino de Ciências e Matemática.

A seguir, apresentamos a segunda e última categoria de análise deste artigo, emersa dos textos narrativos dos sujeitos.

\section{IDENTIDADES CULTURAIS E A FORMAÇÃO PÓS - GRADUADA}

As diferentes visões de mundo e intenções de pesquisa dos mestrandos que se entrecruzam no espaço de formação de professores impregnam o sentido dos intercâmbios em meio aos quais se desenvolve a construção de significados de cada indivíduo. Podemos dizer então que acontece um verdadeiro entrecruzamento de culturas (PÉREZ GÓMEZ, 2001).

Entendemos por cultura aquela que se expressa em significados, valores, sentimentos, 
costumes que circundam a vida individual e coletiva da turma do mestrado. Como consequência de seu caráter contingente, parcial e provisório, a cultura não é algo fixo. Deve ser considerada sempre como uma história que pode ser reescrita a cada contexto, que é necessário interpretar indefinidademente.

Diante das vozes dos sujetos envolvidos, vieram à tona duas subcategorias acerca de suas identidades em formação nesse contexto educacional: Formação pós-graduada: espaços de intecâmbio de culturas e $A$ crise de identidades e seu processo identitário no mestrado, as quais passamos a explicitar/analisar a seguir.

\section{FORMAÇÃO PÓS GRADUADA: ESPAÇO DE INTERCÂMBIO DE CULTURAS}

Cada mestrando determina as possibilidades de criação e desenvolvimento interno, de autonomia ou dependência individual. O curso de pós-graduação é uma instância de socialização e lhe confere identidade própria e relativa autonomia, ou seja, possibilita mediação reflexiva das diversas influências que os mestrandos exercem entre si. A própria dinâmica do curso se configura num espaço de cultura crítica (PÉREZ GÓMEZ, 2001), pois nele se alojam disciplinas científicas, filosóficas e temáticas que proporcionam uma viagem às diversas formas de pensamentos e concepções de ciências e educação. Neste sentido, Fernando se manifesta, nos seguintes termos:

Fiz uma viagem no tempo [...] do currículo tradicional ao pós-crítico, de culturas a subjetividades, de Piaget a Vigotsky. Estou convicto de que os desafios são muitos e ainda estão começando.

Por ter contato com as várias formas de pensamento, Fernando se sente fortalecido para enfrentar os desafios, buscando um olhar crítico a partir das mediações estabelecidas nesse espaço, tornando-o mais convicto em tomar posição diante do que lhe é apresentado.

As disciplinas do mestrado e a forma como os professores conduzem suas aulas constituem rica e expressiva teia de culturas e de expectativas por onde transita o sujeito em formação, possibilitando-lhe um período de ativa construção de significados e de sua identidade de mestre, configurando-se este espaço de formação de professores um espaço de intercâmbios acadêmicos e pessoais (PÉREZ GÓMEZ, 2001).

É tão intenso o curso de mestrado[...] que no meu dia-a-dia me surpreendo comigo mesmo, como, por exemplo, ao encontrar meus colegas de trabalho[...] nossas conversas informais acabam em conversas discursivas teóricas formais (Fernando).

Tomando como parâmetro os ritos, as formas de organizar o espaço e o tempo, os consensos não discutidos, as ideias onipresentes, as expectativas não-questionadas e os códigos nesse contexto investigativo, tudo se constitui como elementos fundamentais na formação de Fernando, que se articula no cruzamento entre o acadêmico e o pessoal repercutindo em ações extra-muros acadêmicos ao encontrar seus colegas de trabalho, estimulado por uma motivação interior e pela sensibilidade ante a decisiva influência socializadora e educativa dos múltiplos elementos tácitos e imperceptíveis que constituem a vida cotidiana do curso de formação pós-graduada.

\section{A CRISE DE IDENTIDADES E SEU PROCESSO I DENTITÁR IO NO MESTRADO}

A identidade não é algo fixo. Para Nóvoa (2007, p 15), a identidade é um lugar de lutas e de conflitos, ou seja, é um espaço de construção de maneiras de ser e de estar no mundo e na profissão. Desse modo, abordaremos como processo identitário as mudanças interiores expressas pelos sujeitos investigados.

Podemos considerar que, no decorrer das aulas, os mestrandos passam por crises de identidade e entendemos que ela é característica de um contexto de transformação de ideias, de visões, de compreensões acerca de novos conhecimentos, de crenças, de valores, de práticas profissionais, de pesquisa, etc. Essas crises evidenciam-se a partir do momento em que os mestrandos têm contato com as diversas visões de mundo expressas tanto pelos autores 
estudados nas disciplinas como pelos grupos de estudos dos quais participam.

A construção de identidades é um processo complexo, pois ocorre em função da apropriação, pelo sujeito, do sentido da sua história pessoal e profissional. $\mathrm{O}$ curso do mestrado se torna um espaço onde os mestrandos ressignificam suas histórias de vida e formação, reconstituindo identidades, ao tempo em que se apropriam de inovações e produzem mudanças em suas maneiras de ver e conceber a profissão e as novas funções/responsabilidades como Mestres em Educação em Ciências e Matemáticas.

Nós, mestrandos, passamos a nos questionar como sujeito humano e percebemos que a identidade não é um dado adquirido e nem tampouco algo fixo e imutável. Ao identificar tais características, deixamos de ser "centrados" e passamos então a sermos "descentrados" (HALL, 2004, p.23), ou seja, a individualidade passa a ser vivida e concebida de forma diferente. A dúvida emerge e se aprofunda nos descentrando de uma verdade absoluta e das certezas anteriormente aceitas.

O deslocamento do sujeito provocado pelo contato com as novas visões de mundo e reflexões sobre sua prática pedagógica, passa por descentrações configurando-se em crise de identidade. Fernando entra em contato direto com teorias sociais das ciências humanas que sobre ele exercem impactos.

Rompi com velhos paradigmas e participo hoje de uma nova escola, pois achava que só existia uma verdade absoluta (Fernando).

E cujo maior efeito se dá ao descobrir-se um sujeito cartesiano. Reconhece em si essa característica, ao afirmar que para ele só existia uma verdade absoluta.

O passado e o presente exercem um importante papel nesses eventos. A contestação do presente busca justificação para a criação de novas/futuras identidades, evocando origens e fronteiras do passado. Os conflitos internos formulados estão, com frequência, concentrados nessas fronteiras, nas quais sua identidade de educador é questionada e contestada, podendo "mexer" no passado, pois ele é resignificado com os debates, leituras e estudos realizados.

Podemos dizer que a identidade ora manifestada pelos mestrandos desta pesquisa gravita em torno daquilo que Robins, citado por Hall (2004) - seguindo Homi Bhabha -, chama de "tradução". Com as leituras e atividades reflexivas realizadas no mestrado emergem identidades culturais que se encontram suspensas, em transição, entre diferentes posições - na identidade de professor e agora na identidade de mestre em construção - buscando apoio nessas identidades pelas quais transitam, e que são produto desses cruzamentos culturais. A identidade de tradução retém fortes vínculos com suas práticas educativas, mas sem a ilusão de permanecer no passado. Percebemos que Letícia se encontra na identidade de tradução ao se reportar ao conhecimento adquirido que lhe permite perceber diferentes naturezas de conteúdos a serem ensinados, deixando claro que se encontra em processo de transição entre a identidade de professora e a de aluna, ao dizer:

\footnotetext{
Permito aliviar-me quando acredito ser importante dar ênfase a determinados conteúdos acadêmicos, ou seja, [...] a tentativa de ensinar conteúdos específicos não é intrinsecamente negativa, tudo depende de quais conteúdos se quer ensinar (Letícia).
}

Ela se sente aliviada ao perceber que o caminho escolhido em alguns momentos de sua prática vai ao encontro de concepções defendidas por alguns autores estudados, como, por exemplo, quando entra em contato com os conteúdos factuais, conceituais, procedimentais e atitudinais e percebe que em sua prática docente prioriza conteúdos conceituais. Encontra apoio epistemológico - que de acordo com seu entendimento - revela que os conteúdos conceituais são importantes. Entretanto, tudo depende de quais conteúdos se quer ensinar. Ao se expressar deste modo, permite-nos perceber indícios de que agora entende que o professor tem possibilidade de selecionar os conteúdos a serem ensinados, sobre o que possivelmente antes não tinha clareza.

Essa identidade provisória pela qual está passando é fruto de uma negociação entre as concepções educativas com as quais teve contato antes e durante os estudos pósgraduados, sem aceitar de imediato as novas ideias e sem perder completamente sua 
identidade anterior. Trata-se de um processo de reflexão, que envolve resistência e abertura ao novo. As pessoas que passam por esse processo têm sido obrigadas a renunciar ao sonho ou à ambição de redescobrir a "verdade perdida", pois existem várias verdades. Elas se encontram irrevogavelmente traduzidas (HALL, 2004).

\section{LANÇANDO OLHARES SOBRE A FORMAÇÃO PÓS - GRADUADA: À GUISA DE CONLUSÃO}

Buscamos desvelar os sentidos e significados que os mestrandos atribuem ao seu processo de formação pós-graduada. Podemos inferir que os os sujeitos investigados revelam ser (co) responsáveis pelos seus processos de formação, acreditando que $o$ ser em formação só se torna sujeito no momento em que a sua intencionalidade é explicitada no ato de aprender e em que é capaz de intervir no seu processo de aprendizagem e de formação (JOSSO,1988 p. 50), além de expressar prazer e busca por mudanças em suas práticas.

À medida que expressam seus pensamentos, ativam a imensa gama de significados que atribuem a si e a seus sistemas culturais. Este processo de reflexão educativa pelo qual os sujeitos estão passando tem promovido (re)construções de suas diversas identidades, tendo em vista que o intercâmbio estabelecido forma uma rede de significados compartilhados que possuem sentidos individuais e coletivos.

Nessa perspectiva, percebemos que os mestrandos durante esse processo de formação tornam-se ávidos por outras/novas ações docentes, no intuito de por em prática os novos $\begin{array}{cccccccccccccccc}c & o & n & h & e & c & i & m & e & n & t & o & s\end{array}$ construídos/reformulados/reforçados nas interações vivenciadas, nas leituras e nos intercâmbios culturais proporcionados nesse espaço de ensino e aprendizagem, tanto em termos da docência, quanto da pesquisa.

Compreendemos este estudo como inacabado, como etapa de um processo de reflexões acerca de nossas experiências de formação. Concordamos com Gonçalves (2005, p.78), quando diz que "o pensamento reflexivo não ocorre de forma automática: é uma atitude intencional sobre fato que gera incerteza ou dúvida, gerando ideias, dúvidas, questionamentos, hipóteses, avaliações, julgamentos e conclusões".

Ao refletirmos sobre as narrativas dos sujeitos envolvidos, interpretamos como eles experimentam o mundo, vivemos seus relatos e, como consequência, também refletimos sobre nossas próprias trajetórias de vida e nos interrogamos sobre nosso percurso de desenvolvimento pessoal e profissional, buscando cada vez mais aprender a aprender.

\section{REFERÊNCIAS}

ALARCÃO, Isabel. Professores Reflexivos em uma escola reflexiva. $5^{\mathrm{a}}$ ed.São Paulo: Cortez, 2007. (Coleção Questões de Nossa Época; v 104.

BENEVIDES, Araceli. O que revela o discurso de professores sobre a sua leitura durante um curso de formação de professores. In: Expressão. Mossoró, 33 (1-2), p.9-15, jan./dez.

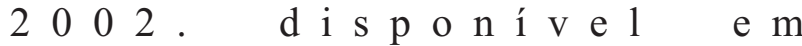
$<$ www.uern.br/pdf/RevistaExpressao/RevistaE xpressao_2002_1.pdf > Acesso em: 17 abril. 2008.

COLL, Cezar, MARCHESI, Álvaro, PALÁCIOS Jesus e colaboradores (Org.). Educação: Desenvolvimento Psicológico e Psicologia da Educação Escolar. Tradução: Fátima Murad. 2. ed. v. 2. Porto Alegre: Artimed, 2004. p. 294-308.

CONELLY, F.M; CLANDININ, D.J. Relatos de experiência e investigação narrativa. In: LARROSA, J. et al. Déjame que te cuente: ensaios sobre narrativa e educación. Barcelona: $\mathrm{L}$ a e r t e s . 1995 . p p $11-59$

FIORENTINI, Dario; NACARATO, Adair ( org.). Cultura, formação e desenvolvimento profissional de professores que ensinam matematica: investigando e teorizando a partir da prática. São Paulo: Musa Editora,Campinas,: GEPFPM-PRAPEM-FE/UNICAMP, 2005.

FREIRE, Paulo. Pedagogia da Autonomia: Saberes necessários à prática educativa. 33 ed. São Paulo: Paz e Terra. 2006. Col. Leitura. 
GONÇALVES, Terezinha Valim Oliver. Formacão Inicial de Professores: Prática docente e atitudes reflexivas. In: AMAZÖNIA Revista de Educação em Ciëncias e Matemáticas. v.1, n.1-Jan./Jun. 2005. p.73-79.

HALL, Estuart. A Identidade Cultural na Pósmodernidade; Tradução: Tomaz Tadeu da Silva, Guacira Lopes Louro. 9 ed. Rio de Janeiro: DP\&A, 2004

IMBERNÓN, Francisco. Formação docente e profissional: formar-se para a mudança e a incerteza. 5.ed. São paulo: Cortez, 2005.

JOSSO, Marie-Cristine. Experiências de vida e formação. Trad. José Claudino e Júlia Ferreira. São Paulo: Cortez, 2004.

MORAES, Roque e GALIAZZI, Maria do Carmo. Análise textual discursiva. Ijuí: Unijuí, 2007.

NÓVOA, Antonio. A formação tem de passar por aqui: as histórias de vida no projecto Prosalus. In: NÓVOA, Antonio e FINGER, Mathias. Tradução: Maria Nóvoa. Odivelas: Ministério da Saúde. 1988.

. Os professores e as histórias de suas vidas. et al. 2a. ed. Porto Editora: Portugal, 2007. In: NÓVOA, Antonio. Vidas de professores. p. 11 - 30. Col. Ciência da Educação.

. (Org.) Os professores e a sua formação. Lisboa: Publicações Dom Quixote, 1995.

PÉREZ GÓMEZ, A.I. A Cultura Escolar na Sociedade Neoliberal. Trad. Ernani Rosa. Porto Alegre: Artimed, 2001.

SANTOS, 2005. B.S. Um Discurso sobre as Ciências. $3^{\mathrm{a}}$ ed. São Paulo: Cortez. 